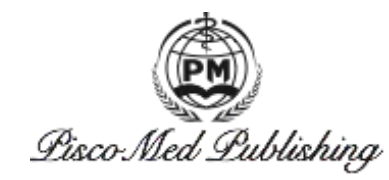

Original Research Article

\title{
How Could Huawei Grow to the Largest Telecommunication Service Providing Company in Burma
}

\section{Zhiyuan Guo*, Zihan Liu}

Department of Architecture and Civil Engineering, City University of Hong Kong, Kowloon, Hong Kong, China. E-mail: guozhiyuan123456@hotmail.com

Abstract: From the point of telecommunication service providing, the paper analyzed three critical factors which help Huawei become the largest provider in Burma. They are models of operation, modern project management method, and corporation culture. Burmese project is only a microcosm of Huawei's overseas business. It is also a perfect interpretation of the overseas development history of a Chinese private enterprise that is full of fighting spirit.

Keywords: Huawei; Telecommunication Service; Burma

\section{Basic introduction and background of Huawei company}

\subsection{About Huawei}

Founded in 1987 by Ren Zhengfei, Huawei Technologies Co., Ltd. has grown from an original communications product agent to a supplier of communication network technology research and development, production and sales. Huawei's products mainly involve switching networks, transmission networks, wireless and wired fixed access networks and data communication networks, and wireless terminal products. Huawei can continuously innovate according to the needs of customers, providing cost-effective ICT solutions and services to telecom operators and enterprise consumers in all countries. Nearly one-third of the population in more than 150 countries around the world use Huawei products. Huawei has now become the world's leading supplier of communications equipment and smart phone manufacturers $^{[1]}$.
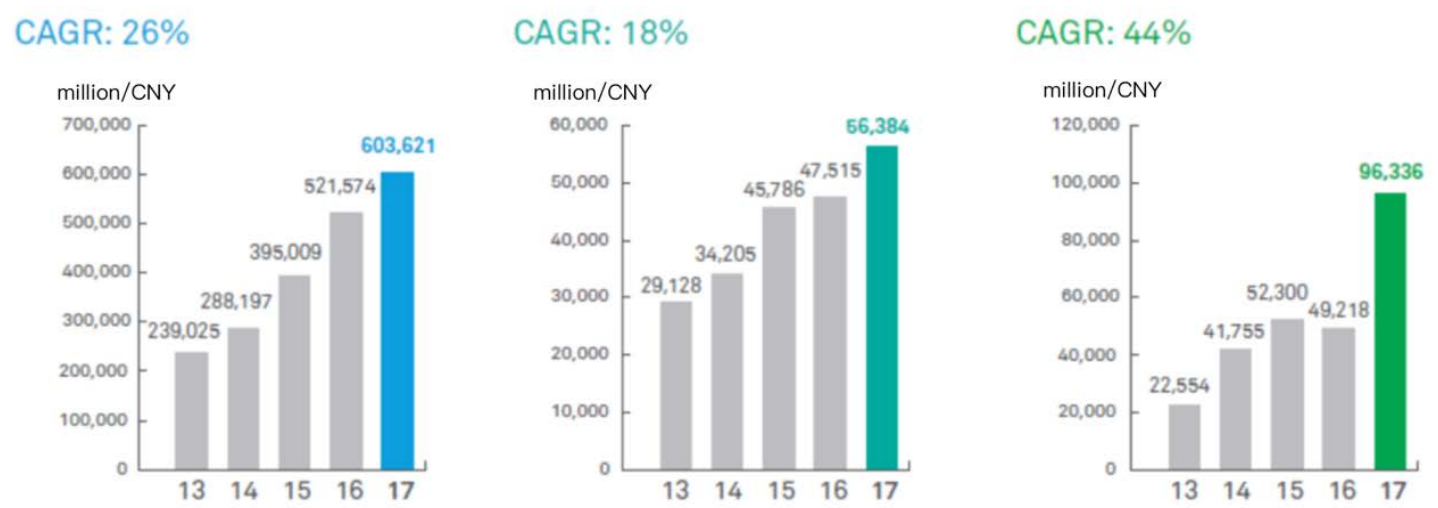

Figure 1. Huawei profits comparison ${ }^{[2]}$.

Copyright (C) 2020 Zhiyuan Guo and Zihan Liu

doi: 10.18282/bam.v2i2.1369

This is an open-access article distributed under the terms of the Creative Commons Attribution Non-Commercial License

(http://creativecommons.org/licenses/by-nc/4.0/), which permits unrestricted non-commercial use, distribution, and reproduction in any medium, provided the original work is properly cited. 
In recent years, Huawei got great profits and maintained good operation conditions. Figure 1 shows the financial status of Huawei.

\subsection{Service scope in Burma}

Based on its strong technical foundation, Huawei provides almost all possible communication service types for Myanmar. On the basis of infrastructure construction services, Huawei has rapidly developed wireless access, fixed intervention, core network, transmission network, data communication and Huawei's terminal multi-dimensional integrated communication network. In addition, Huawei also established the School of Information and Network Technology at the Ding Yin University of Technology in Yangon in 2016. It encourages students to participate in Huawei’s vocational and technical certifications and cultivates talents for the society by teaching Huawei courses to universities free of charge.

\section{Models of operation in Burma}

\subsection{Providing equipment at low rate to win tenders}

Huawei actively responded to the national “The Belt and Road” and "Going out” strategies, and won the bidding project of communication networks in many countries through strong business operation methods and good brand image. In these developing countries, Huawei can consider the problem in the long run from the perspective of operators, and provide operators with comprehensive maintenance services for the next ten years to ensure the stability of the communication network. The premise of all this is that Huawei has won most or even all of its targets with almost absolute price advantage, which has reduced a large investment budget for operators in the later stage of operation and maintenance. Based on equipment upgrade services, operators share profits together. This forward-looking vision undoubtedly demonstrates Huawei's strategic vision and achieves the goal of maintaining long-term business cooperation by establishing Huawei standards.

\subsection{Managing contractor model in portfolio implementation}

Managing contractor and construction management are two common ways which are used in the construction industry recently; different way is suitable to specific scenario according to its own characteristics. But the scope of the definitions becomes less clear in order to meet the unique requirements of customers. Under construction management model, the contractor will be responsible for nearly all work, and it is his responsibility to create the contract relationship with different subcontractors and take the liability of the work quality. But under managing contractor model, the contractor will manage all relatives on site and arrange the work properly to complete the construction work on time and ensure the quality as well.

But for Huawei, who plays a role as a managing contractor, should manage the work well and ensure to accomplish the client's target, certainly the contractor will not conduct the construction work himself, all the construction work will be done by kinds of subcontractors including the tower erection team, CW team and TE installation team, power team and so on.

\subsubsection{Self design and specification making to show the unique professions}

As the world's largest supplier of communication equipment, Huawei has a very advanced technology and management level in the manufacture and maintenance of communication equipment. But for a complex large-scale infrastructure construction project, a single management method and technology is clearly not up to the complexity of the project. As a managing contractor, Huawei assists owners in selecting the contractors of each branch by means of bidding, and employs professional base station civil engineers to form their own design team, based on the level of actual terrain and infrastructure with dozens of different equipment combination scenarios, and matching the complex and complex indoor and outdoor base station design, reflecting the characteristics of local conditions. For example, in a base station in a city, it is considered that the location of the base station is built on the roof to match the roof-top to save land area, and there is a continuous supply of electricity in the city, which is almost never designed about considering 
solar panel power. For base stations in remote locations or outdated villages, considering the strong sea breeze and humid climate erosion, and the altitude at which the base station is located, the corresponding design spray and solar power are combined with the power supply of DG. Different types of SST and GWT are matched to ensure uninterrupted communication signals.

After the design is completed, the design team will also give a detailed SOP. The SOP will describe the various specification requirements as clearly as possible, and display them in the form of a chart (see Figure 2 for partial SOP).
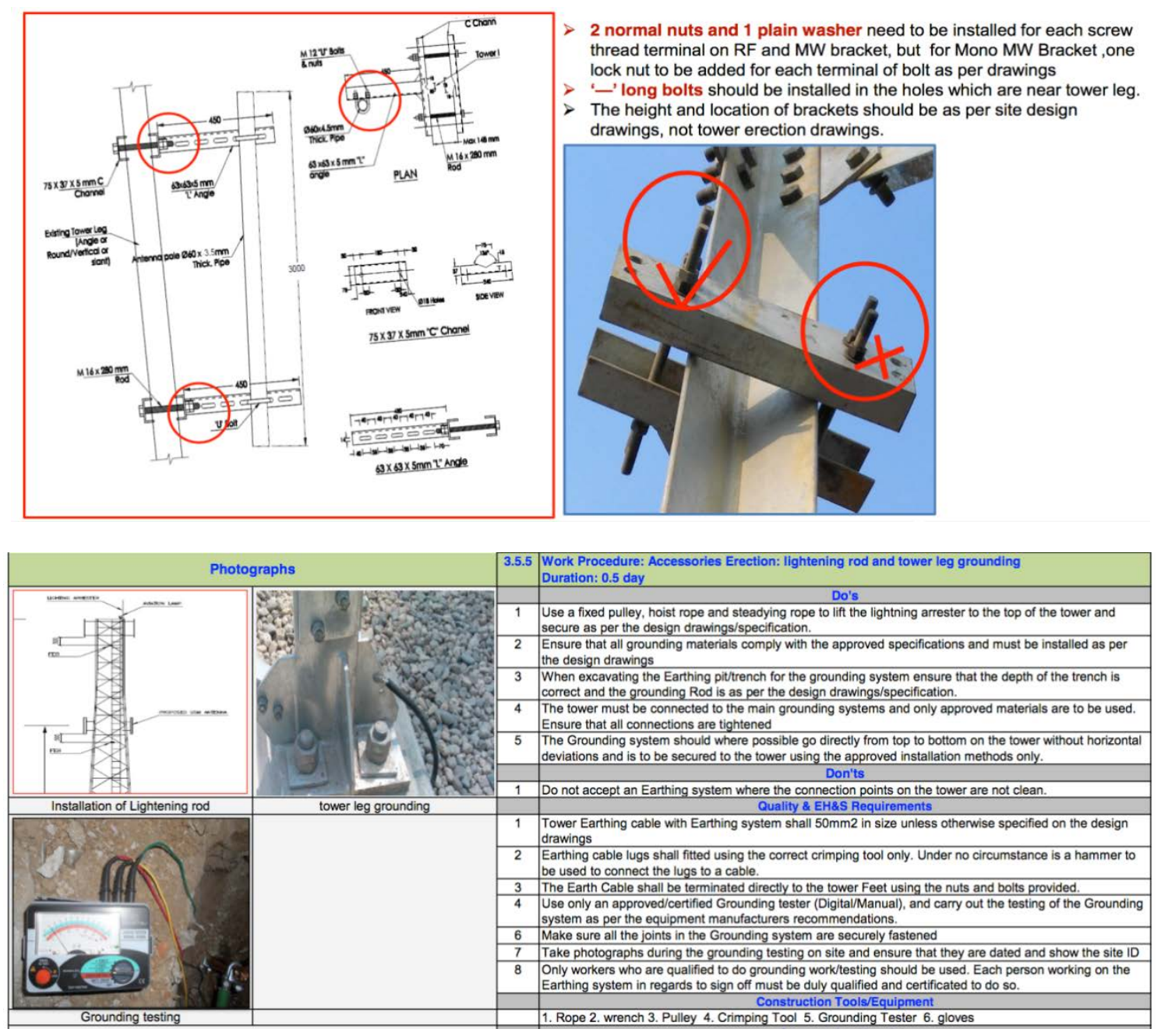

Figure 2. Partial SOP for SST work.

\subsubsection{Construction work to be sub-contracted including CW \& TE works}

For the most important CW work and TE work in the construction of base stations, Huawei is undoubtedly outsourcing all of them, but Huawei's filtering of subcontractors is also extremely strict. It is necessary to consider not only the size of the subcontracting enterprise and the level of market possession, but also its technical expertise, funding level and qualifications. Huawei's own professional consulting company searches all the companies that meet the requirements in the industry, establishes subcontractor management files, conducts measurement and evaluation of subcontractors, and combines the performance of subcontractors and Huawei's past business cooperation to select global golden suppliers and excellent suppliers, and the poor performers were blacklisted, and then cut off from doing business with them.

In this background, a large number of Chinese companies responding to the "The Belt and Road" and "Going out" calls by the Chinese government, with their strong asset background and long-term business experience, and quickly established a cooperative relationship with Huawei and occupied almost all of the overseas market. The communication 
tower supplier represented by Shandong Luneng Taishan, the equipment installation and civil construction providers represented by China Communications Service (CCSI), several state-owned enterprises including Petro China and Sinopec have quickly joined forces and quickly seized the overseas market.

\subsubsection{Own equipment to be served in all contracts}

As we all know, Huawei has been expanding overseas since 2008, and the largest part of its overseas revenue comes from equipment sales. Huawei started from the sales of telephone switches, and now has strong communication equipment research and development and production capacity. Independent innovation has undoubtedly become Huawei's most precious wealth in the era of knowledge economy. In the previous overseas projects, Huawei always appeared in the presence of equipment suppliers in the face of the operators of various countries. In the fierce market competition, the risk of being replaced by customers and main contractors was at any time. Manufacturers such as ZTE, Ericsson, Siemens and Nokia have become Huawei’s most troublesome competitors. Nowadays, Huawei, which is not to be outdone, often appears in the international engineering contracting market as the main contractor, from "selected by others" to "select others". The biggest advantage is that it can establish the long-term equipment sales channels by setting up Huawei's standards. Once Huawei’s standards are set up overseas, operators will be bound from this point of time, so that Huawei equipment must also be used when upgrading equipment and upgrading operations.

\subsection{Operation and maintenance}

Of course, in order to maximize profits and enhance the competitiveness of Huawei's overseas companies, Huawei has established a local team and trained local engineers to stabilize overseas markets. After the establishment of a mature overseas representative office, there are often only a few Chinese employees, and the rest are local employees. In this way, the labor cost is greatly saved, and the emergency response capability of the representative office is also raised.

\section{Modern project management methods to be used based on ISDP}

\subsection{Safety management}

Safety issues are of the utmost importance in any construction. To ensure safety and quality, Huawei has established a specialized QEHS (quality, environment, health and safety) leadership team to comprehensively plan, organize, lead, coordinate and control safety. From the worker health checklist to be completed on the daily construction site to the daily construction work risk prediction table, not only the on-site supervision engineer needs to give detailed instructions to each worker, but also to upload photos to the system in the form of a QEHS leading group in the second inspection evaluation. During the construction process, Huawei also has strict requirements on the production tools and personal protective equipment (PPE) used by workers. For example, the safety helmet must comply with the EN397 standard, and the safety shoes must be with steel plates to meet the relevant British standards. Even before each engineer or worker joins the Huawei construction team, he has to undergo a series of Huawei training and get the Huawei-certified QEHS certificate through Huawei exams to become a part of Huawei’s construction team.

\subsection{Quality control}

In order to comprehensively and timely control the quality and safety of the project, and to engage in the combination of pre-control, in-process control and post-event control to ensure the quality and safety of the project, Huawei not only strictly requires the construction according to the drawings and specifications, such as strictly controlling the water-cement ratio to ensure the slump test cannot be used in engineering. When the Tower erection is completed, and the first level of tower is not completed, the verticality of the tower is checked by the theodolite and the offset is corrected in time.

\subsection{Schedule control}

Under normal circumstances, the civil engineering project duration of each base station is 45 days, and the equip- 
ment installation time is 4 days, plus other materials transportation and inspection and debugging time, etc. Huawei guarantees that a base station must be completed within two months. It seemed impossible to accomplish but the Huawei project team has achieved this through effective communication and coordination and advanced management methods, saving customers' time and costs, and earning a reputation and market for themselves.

\subsection{Supplier management}

Huawei is able to guarantee the outstanding delivery of its overseas business, thanks to its strong global supplier. For the management of these suppliers, Huawei has established a series of effective supplier management methods, including regional evaluations and global evaluations. Those suppliers who have repeatedly received Huawei's red or yellow card warning will be eliminated with no hesitation. For those new companies that want to become part of Huawei's supply chain, Huawei will also give it a corresponding evaluation period, and the company that has passed the evaluation will eventually become a Huawei supplier.

In order to ensure the progress of the project, Huawei has a logistics and warehousing center all over the world, and its logistics management capability is also second to none in the industry. Each time the inventory turnover rate (ITO) is shortened, it can save the company 100 million yuan in cost, which requires the information exchange of representative offices, customers, suppliers and logistics centers to be timely and effective.

\subsection{Integrated delivery planning}

In the management of large projects, Huawei can clarify the customer's equipment installation plan, and designate reasonable procurement and construction plans based on this, and focus on materials, resource integration and risk management on the basis of upgrading ITO. Through scientific analysis of the configuration of all parties, comprehensive optimization to promote fairness and efficiency, enhance the ability of large project integration delivery management, and export targeted decision-making processes.

\subsection{All-in-one integrated management}

In order to improve its project management efficiency, Huawei is the first to cooperate with Japan Telecom KDDI in the Myanmar Network Expansion MPT-KSGM Phase 4 project to launch integrated project management software ISDP (integrated service delivery platform), which makes that purchase, logistics, and construction, progress payment, security management, quality control and schedule control are all integrated into one software, and greatly promotes the business interaction between Huawei and suppliers.

\section{The corporation culture of Huawei}

\subsection{The intrinsic value of Huawei}

Huawei's ability to achieve such great achievements is inextricably linked to Huawei's corporate culture. Ren Zhengfei, a soldier from the military, played the military's strict discipline and fighting spirit in the management of enterprises. This is also the root of the "wolf" culture. It is this kind of quality that creates the spirit of not afraid of suffering and hardships, which has made Huawei’s rapid development and expansion. Huawei’s overseas road has emerged in Africa, to survive and developing in the business gaps of Western companies, emulate China's revolutionary road of "the countryside surrounds the city, arms seized political power". As long as the contract can be signed, and there is engineering, Huawei will go there with no doubt. In the chaos of the wars and rain of bullets, it can always be seen that the Huawei engineers in the war zone. In this way, overcoming all kinds of difficulties and obstacles, Huawei finally won more and more overseas orders and gradually occupied the global market.

\subsection{The art of multi-cultural management in Burma}

To carry out construction projects overseas, not only various political and economic risks, but also complex cultural diversity should be taken into consideration. According to the religious culture of the project site, cross-cultural project management needs to be carried out, not only to fully respect the culture, customs and religious beliefs of the host 
country, but also to combine corporate culture with foreign cultures to give employees a sense of belonging. If no attention is paid to the details in management, local employees and Chinese employees may have conflicts because of small things.

\section{Conclusion}

In short, Huawei's communications construction project in Myanmar is only a microcosm of its extensive overseas business. The history of Huawei's growth in Myanmar is a perfect interpretation of the overseas development history of a Chinese private enterprise that is full of fighting spirit. We believe that Huawei, which is constantly advancing with the times, will continue to lead the world in the communications industry.

\section{References}

1. Huawei official website [Internet]. Available from: https://www.huawei.com/cn/?ic_medium=direct\&ic_source=surlent.

2. Annual report of Huawei company [Internet]. Available from: https://www.huawei.com/cn/about-huawei. 